\title{
Measuring Flexicurity: Precautionary Notes, a New Framework, and an Empirical Example
}

\author{
Heejung Chung
}

Accepted: 29 January 2011/Published online: 14 February 2011

(C) The Author(s) 2011. This article is published with open access at Springerlink.com

\begin{abstract}
Recently, there has been an increase and abundance of literature measuring flexicurity across countries. However, there is yet to be any agreement on the definition of the key concepts of flexicurity as well as the framework in which to base one's research. Due to this, the outcomes found in the existing studies are rather diverse, far from reaching a consensus, and can be misleading. This paper addresses the issues by first introducing a framework, namely, the various levels and stages of flexicurity, as well as introducing some key issues that should be addressed when doing flexicurity indicators research. In addition, an empirical example is given to show how the framework derived can be used to carry out flexicurity research, and to show how by not regarding these frameworks one can come to misleading outcomes.
\end{abstract}

Keywords Flexicurity · Flexibility $\cdot$ Security $\cdot$ Indicator research · Analytical framework · Efforts state and effects

\section{Introduction}

Flexicurity approaches have been gaining more interest over the past few years. This may be attributed to the success of the so-called Danish model, and to the European Union (EU)'s adoption of flexicurity as a strategy to increase competitiveness while maintaining the European Social Model. Due to these developments, there has been a significant increase in studies that deal with flexicurity indicators both theoretically as well as empirically. Despite this abundance, the discussion concerning a common framework in which to base one's research is lacking. Many, if not most studies, do not base their studies on a solid framework, but rather focus on gathering indicators of flexicurity which are based on incorrect assumptions of what the indicators are measuring (for example CEC 2006b, 2007a, b; Philips and Eamets 2007). This results in numerous numbers of studies in which the results are spurious and conflicting to one another. This paper addresses these

H. Chung $(\bowtie)$

Department of Sociology, Tilburg University, Postbox 90153, 5000LE Tilburg, The Netherlands e-mail: h.chung@uvt.nl 
issues by introducing a framework, namely the levels and stages of flexicurity, which should be used when examining indicator of flexicurity, as well as some additional points to be taken into consideration when working with flexicurity indicators. In addition, the paper provides an empirical example, using macro-level national data from EUROSTAT and OECD, to show how the framework derived can be used to carry out flexicurity research. Through the empirical example, we can see how one can come to misleading outcomes if the study is not based on a proper framework, with sound theoretical backgrounds.

The structure of this paper is as follows. Section 2 examines some of the key issues that need to be taken into consideration when measuring flexicurity. From this, a new framework that can be used to measure flexicurity across countries will be proposed. This section also includes the examination of other problem aspects one comes to face, such as the issue of weighting and composite indicators. In the third section, based on the framework and issues addressed in the previous section, some preliminary analysis will be done, to show how one can use the framework and the aspects of caution given in this paper, through the use of empirical data. The paper ends with some conclusions and discussion points in the last section.

\section{Key Issues of Measuring Flexicurity}

In this section, I will examine some of the key aspects that should be taken into consideration when measuring flexicurity, especially using quantitative data across large numbers of countries. Here the goal is not to provide a state of art on flexicurity indicators, which has already been done (Chung et al. 2009; Viebrock and Clasen 2009), but rather focus on the key questions one should take into consideration when setting forth the task of quantitatively measuring flexicurity across countries.

\subsection{Problems with Defining and Framing Flexicurity}

The first, and foremost important aspect to be aware of when examining flexicurity is the question of which definition and framework to use, thus the process of operationalisation. Currently, there are many definitions of flexicurity, as there are many researchers engaged in the research of flexicurity, and there are no agreed-upon definition (see Viebrock and Clasen 2009). The definition of flexicurity can range from any combination of any forms of flexibility and security, to the combination of more precise elements of labour market flexibility and security policies. The most commonly used framework and definition is the so-called 'Flexicurity matrix' by Wilthagen and Tros (2004:171), the four components of flexicurity identified by the CEC (2007b), and the Danish golden triangle by Madsen (2004).

The choice of definition and framework to use is entirely up to the researcher's discretion and interest. However, one must be aware of the consequences of the choice of definition and frameworks. By taking up a certain definition and framework, a researcher is consciously taking a decision to put emphasis on a certain aspect of flexicurity. It is demanding to include all aspects of flexicurity components, especially when trying to quantitatively measure flexicurity across countries (Viebrock and Clasen 2009:310). However, if we were to take the narrow definition of the Danish golden triangle as our flexicurity definition, we are presuming that there is only one path towards flexicurity, which goes against the argument put forward by CEC in its 2007 document, which puts forward the idea of "different pathways"(CEC 2007b). In other words, a narrowly defined 
approach will not be able to measure the functional equivalent policy alternatives used in other countries in order to achieve flexibility while providing security. In addition, the framework one decides on will also impact the amount of weight given to each concepts of flexicurity. For example, when using the flexicurity components approach as devised by the CEC (2007b), the concepts of active labour market policy (ALMP) and life-long learning (LLL) are separate components. In comparison, this is considered as one component in the Danish flexicurity model, as being part of a larger ALMP strategy. Thus, when using the flexicurity components approach, by default more emphasis is put on labour force training aspects of flexicurity.

There is not a solution to this problem, due to the fact that it is not a problematic issue in itself. It is only when the researcher does not reflect on the limitation of the definition and framework he or she has chosen, and argues that the outcomes found can be applicable for all flexicurity definitions, than it becomes a problematic issue. Overall, all studies that measure flexicurity cannot but be based on certain political viewpoints due to the fact that when choosing the definition and framework, one is choosing what is or should be flexicurity.

\subsection{Problems with the Framework 1: Stages of Flexicurity}

After deciding on the definition of flexicurity, one must then decide which stage or which relationship between the stages of flexicurity they want to measure. Flexicurity can be understood as both a policy strategy and state of affairs (Wilthagen and Tros 2004: 169). It is, on one hand, a policy strategy to enhance the flexibility and security in order to achieve good labour market and social outcomes. However, on the other hand, it is a state of affairs where achieving flexicurity could be the goal. Borrowing the elements of the notions of the policy chain or policy cycle (Castonguay 2009; Spicker 2006), in this paper I apply the distinction between efforts, states, and effects to capture the various stages at which flexicurity policies can be measured. As a first step, this staged process is displayed in Fig. 1 .

The efforts of flexicurity pertain to what is done to enhance flexibility and security within a country. The efforts can take the form of financial, legal and other measures, including arrangements and institutions as embedded in laws (e.g. Employment Protection Legislation; regulation on wage and working time) and policies, and practices of various actors at various levels such as companies (working time arrangements; holidays), as well as individual efforts to enhance one's own flexibility or security (such as private savings). This leads us to the issue of the levels of flexicurity, which will be elaborated later on in this paper. The second phase is the actual state of flexibility and security, which concerns how flexible and how secure the subject under investigation is. In the case of security, since

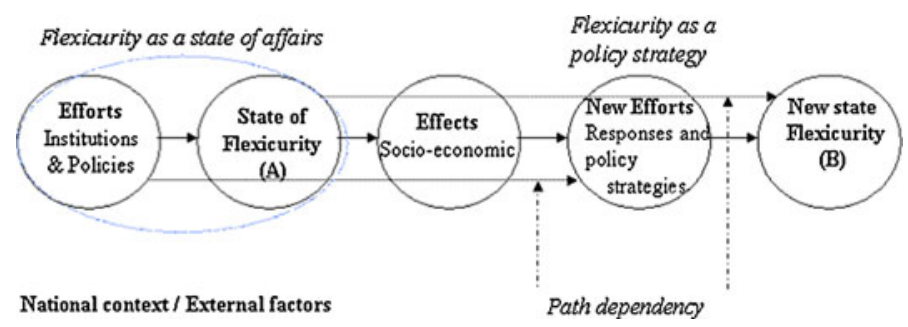

Fig. 1 Efforts, states and effects of flexicurity Source: Adopted from Bekker and Chung 2009 
the goal of flexicurity policies is to provide sufficient level of security for citizens, the state of security is, in itself, an effect or an outcome of flexicurity policies. For example, income security is one of the most important goals of flexicurity policies. Thus, an individual or an aggregate of individuals having income security is a measure one can use to examine policy achievement. In the case of flexibility, the goal of flexicurity policies are not per se to have a flexible labour market, but flexible markets are only means in which to achieve a goal, may it be higher employment rates or higher productivity rates. Some security states can also be means in which to achieve an indirect goal in the policy agenda. A good example of this would be the drop of fertility. A country can try to enhance income or combination security of its population to tackle the issue of low fertility. Drop in fertility rate in itself is not a security state, but, is an effect of (the lack of) security. In these cases, it is useful to distinguish between the state and effect and challenges of flexicurity. Effects are socio-economic performance results that come from individuals and companies being in a certain level of flexible and secure state. Here, effects are not the direct or sole outcomes of the flexicurity efforts, but refer to the indirect outcomes or wider impacts mediated through policies, the national context and external factors, such as those raised by low fertility rates or adverse economic shocks (such as the credit crunch). Challenges of flexicurity can be understood as the gap between the goals set when the flexicurity policies were initiated, and what it has achieved. These achievements can be seen through examining flexibility effects, or security states and effects as mentioned in the previous paragraph. Challenges can also include problems that may arise indirectly due to the states and effects of flexicurity.

The reason why these analytical distinctions are necessary is because although the various stages influence one another, they do not necessarily correspond completely to one another. Institutions such as existing laws and policies are efforts to develop a certain character within the labour market of the country in question. However, policies which aim to achieve certain goals do not necessarily translate into actual practices, ${ }^{1}$ and actors will use different methods to overcome legislative restrictions. ${ }^{2}$ Thus efforts do not always bring the same states of flexicurity. In addition, similar states of flexibility and security will bring about different effects and respective challenges depending on the different national contexts. In other words, these distinctions are crucial to examine what is truly going on in European countries with regard to flexicurity, and mixing the various stages has the danger of providing meaningless outcomes. Later on in this paper, it is empirically shown how the different stages do not correspond to each other.

The Employment Commission of the European Commission, in its recent document, also sets forth a similar framework of input, process, and output (EMCO 2009). Input indicators are similar to efforts in that they are quantitative assessments of rules and regulations, for example concerning benefit coverage or provision of services. On the other hand, process indicators are the shares of particular groups of persons affected by or participating in policy measures. In our framework, this is considered a part of efforts, since the population affected in most cases are driven by the national institutions. Output indicators are similar to that of our state and effect, and the EMCO group does not make a distinction between the two. This is problematic due to that, as mentioned previously,

\footnotetext{
${ }^{1}$ In a study done by the TUC (Trade Union Congress), in the UK, two-thirds of workers who work longer than 48 hours have not signed the opt-out agreement, which is against the national labour regulations (TUC 2005).

${ }^{2}$ For example, companies in countries that have high cost of firing workers, enhance flexibility through the use of temporary employment (Dolado and Jimeno 2002; Polavieja 2006).
} 
in some cases flexicurity states are goals in themselves, whereas in other cases they can be means to achieve certain goals. Thus it is not appropriate to group the goals and means in the same category. In addition, for researchers it is crucial to examine how different situations or states of flexibility and security could lead to different labour market outcomes or effects, especially given that certain flexibility and security states are means to achieve certain goals.

Also, similar to the framework depicted here is the one drawn by the ILO for the measurement of employment security (Dasgupta 2001). In this paper, behaviour indicators, contractual indicators and governance indicators are distinguished in measuring employment security. Behavioural indicators relate to certain behavioural characteristics in the labour market to measure stability of employment, such as average length of employment, labour turnover and rate of separation from employment. Contractual indicators use the information of the types of contracts used by companies to calculate the proportion of employment with non-stable contracts, or non-regular contracts. Governance indicators include the legal provisions that ensure various forms of employment protection. Governance indicators are considered effort indicators in our framework, whereas behavioural indicators are part of states. Contractual indicators are proxies that can measure company level efforts to enhance flexibility in the company. Although the distinction made by the ILO is suitable when the sole focus is on employment or job security, it is not appropriate when examining flexicurity overall. This is due to the fact that although contractual indicators may have an important role when examining job security, it is not as important when examining other aspects, such as income security. In addition, in the framework derived by the ILO, categories derived do not reflect the time dimension or the relationship between the different categories. This is not the case in the Effort-States-Effects \& Challenges (ESC) model.

The relationship between the various stages of flexicurity can be understood in terms of policy processes. Efforts made for flexicurity impact the state of flexicurity, which will affect the effects that are derived from the states. Flexicurity effects, along with the past institutional characteristics of a country, bring on new efforts, thus responses and new policy strategies, to overcome the challenges of a country or to eliminate the negative effects of state A. State A then evolves through the new efforts taken to the new state B. The initial efforts, in the first circle on the left in Fig. 1, and the state of flexicurity, the second circle, can be interpreted as the state of affairs of flexicurity. Flexicurity as a policy strategy, the efforts taken in response to the state of affairs of flexicurity, can be represented as the second circle from the right. When strong similarities can be observed between the initial efforts and the additional efforts taken at a later stage, we can consider the policies to be path dependent. In other words, welfare state institutions are selfenforcing and past decisions impact the set of new decisions chosen (Pierson 2004). Alternatively, a significant difference between previous and later efforts can indicate a development of path deviation.

Examining the previous literature on flexicurity indicators, there seems to be no distinction of the flexicurity stages, and no clear frameworks have been developed. In the case of Philips and Eamets (2007), and in the Communications on flexicurity (CEC 2007b), all three stages, efforts, states, and effects, are included in the analysis without clear distinctions. In the Employment in Europe (EIE) 2007 report (CEC 2007a), efforts and states were included simultaneously. Some of the studies do mention the institutional versus factual flexicurity to distinguish between policies and practices (for example, Muffels et al. 2008; Seifert and Tangian 2007). However, even then the studies only distinguish between the employment protection legislation (EPL) index and other indicators and components. 
The problem with confusing the various stages of flexicurity is that it becomes unclear what exactly is being measured in the analysis. Are we examining the efforts made in each country to enhance flexicurity, or are we examining the flexibility and security states of the countries, or their effects? If we include both efforts and states of flexicurity simultaneously in the analysis, we are presuming that they mirror one another. However, flexicurity efforts made do not necessarily translate into flexibility and security states, because there are other (external) factors that come into play in this relationship.

\subsection{Problems with the Framework 2: Levels of Flexicurity}

In addition to defining the stages at which flexicurity can develop, one must distinguish between the various levels at which flexicurity can be examined. Flexicurity policies are usually observed within national as well as international governance systems, but they can also emerge at the sector and company level (Klammer and Tillman 2001; Wilthagen 1998; Wilthagen and Tros 2004). Thus, it is important to clarify the level of flexicurity one intends to measure.

In the document by the ILO measuring employment security, Dasgupta puts forward three relevant levels one should take into account when deriving indicators to measure employment security. The levels are national-macro level, industry-meso level, and lastly individualmicro level (Dasgupta 2001). Although the second level is named industry level, it is noted that this level entails company practices at the enterprise level. Based on the regulation implementation level distinction of Anxo and O'Reilly (2000), I add two more level to identify five levels of flexicurity implementation and measurement. Firstly, there is the supranational level, where regulations are implemented through European Union Directives, such as the Working Time Directive. Secondly, there is the national level, where flexicurity is implemented via universal application of statutory legislation, such as labour laws and other related social security laws and policies. Thirdly, there is the branch or industry level at which regulations are implemented through collective bargaining applied to a range of firms or sectors. Fourthly, there is the company level, where regulations are implemented through corporate policies and both formal and informal bargaining between the individual employer and employee. The fifth and final level is the individual level, which includes the take up of particular arrangements by an individual. The practices at the individual level materialise when the individual makes efforts to enhance one's own flexibility or security, or when he or she takes up, or is enforced to take up a certain flexibility or security arrangement. As we can see in the framework in Fig. 2, industry and company levels are separated unlike as it is in the ILO framework. This is because both industry and company levels are important levels to take into consideration when examining the development of flexicurity efforts.

Figure 2 displays the various levels at which flexicurity research can focus on, and the indicators the measurement of flexicurity can utilize. The arrows in this figure signify the relationship between the higher levels and the lower levels. Higher level regulations can affect the practices/regulations at the lower levels. However, the higher levels do not always restrict the practices of the lower levels. In many cases, the lower level practices go beyond

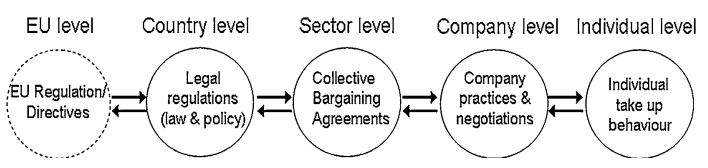

Fig. 2 Various levels of flexicurity

Source: Bekker and Chung 2009 
institutional regulations and may set up new regulations, or not adhere to institutional restrictions given. For example, companies do not always have to adhere to legal regulations or to collective agreements concluded at the sector level. They might use flexibilities afforded by opt-out clauses or operate outside legal boundaries. On the other hand, not all companies make use of the various flexibility options made available in the regulations when they are not deemed necessary or suitable for the company's needs. Companies may also provide more security than the national and sector-level regulations require. It has been shown that in countries where public provisions of work-life balance policies are near absent, one can observe larger employer involvement (Den Dulk 2005; Evans 2002). Also in case of flexicurity and working time flexibility strategies we can see that companies act rather autonomously from their institutional environments (Bredgaard and Tros 2008).

For this reason, it is important to specify exactly which level of flexicurity one is examining. In some countries flexicurity policies are determined by national actors at the national level, whereas in others the initiatives are largely taken by sector or company level actors through collective bargaining agreements or corporate policies. Without taking this into consideration, one will not be able to grasp the actual efforts made in regard to flexicurity, nor the actual availability or implementation of these policies at the shop level. Especially the company level can be of importance, due to the fact that company level practices are the final availability of flexicurity options for workers (Chung 2007). Employees themselves, in most cases, cannot autonomously choose various flexicurity options and are limited to those which are used and provided within the companies. Since one of our key interests in flexicurity research is the question of what type of environment workers and individuals are placed in with regards to flexibility and security provision, we cannot disregard the various levels of flexicurity.

One point to note here is that states and effects can only be measured at the individual and company level. Countries or sectors in themselves are not flexible and/or secure. It is only their companies and citizens that can be in a (in)flexible and/or (in)secure position. A sector, country or Europe as a whole is flexible or secure when the individuals and companies within these particular boundaries are on average flexible and secure. Thus, one can arrive at country level flexibility scores, only through the aggregation of individual and company level micro data. For example, when defining high levels of flexibility in terms of high mobility rates, country flexibility score can be derived through using the mobility rates of individuals aggregated to the country level. The same holds true for effects. Using the mobility rate flexibility example, we can presume that the effect of this may be that there is an increase in productivity, which again could only be measured at the individual worker or company level, then aggregated to the country level. More detailed examples will be shown in Sect. 3 with empirical data. Figure 3 shows the model where the ESC model is combined with the various levels of flexicurity.

Most existing studies typically concentrate on national levels and individual levels of flexicurity. Those studies that put emphasis on states and effects of flexicurity (Muffels et al. 2008; Pacelli et al. 2008; and somewhat Philips and Eamets 2007; Seifert and Tangian 2007) tend to focus more on individual levels and their aggregate national averages. Other studies (Bekker and Chung 2009; CEC 2006a, 2007a, b) focus mostly on measuring national level efforts, to examine their impacts on labour market outcomes. This is largely due to data limitations, as there are not many data sources readily available for the analysis of company or sector levels that are also comparable across countries. Obviously, not all studies of flexicurity necessarily have to take all levels into account. For example, if the key focus of a study is on the national level efforts made to enhance flexicurity and on the national institutional context, then national levels can be examined in 


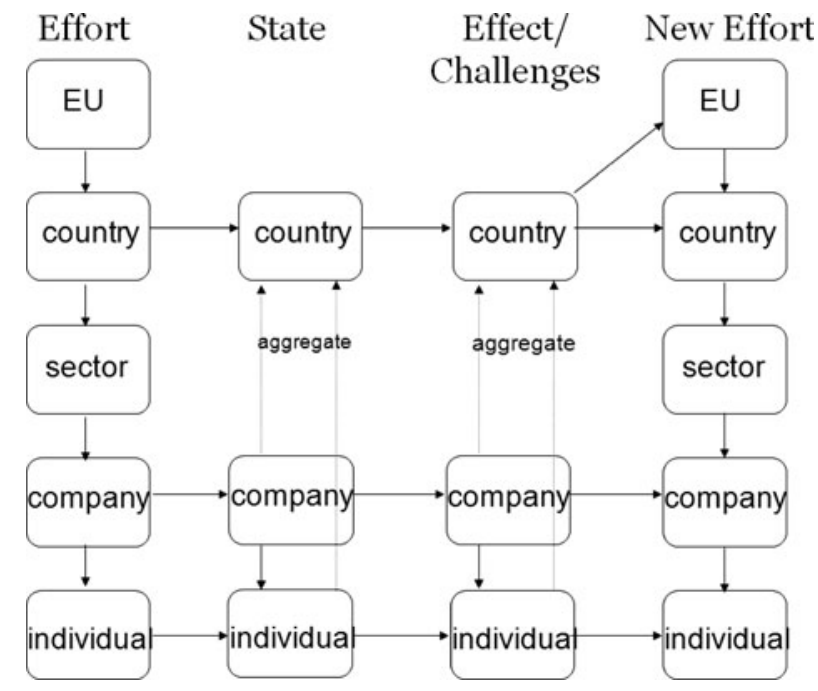

Fig. 3 Combining the stages and levels of security focusing on the country level

Note: The solid lines represent the effects between the levels and stages, and the dotted lines represent how data can be aggregated to be used for cross-national research

isolation (such as the case for Bekker and Chung 2009; CEC 2006a). However, if the purpose of the research is to take into consideration the actual flexicurity efforts made at all levels as well as the situation in which individuals and companies actually operate, examining national level efforts in isolation is insufficient.

\subsection{Problems with Measuring: Simplifying the Complexity}

As we can see from the frameworks described above, measuring flexicurity can be a rather complex task. In order to simplify the complexity into manageable numbers of concepts, while not disregarding the several dimensions that need to be taken into consideration, many researchers use composite indicators (for example, CEC 2006a, 2007a; Muffels et al. 2008; Pacelli et al. 2008; Philips and Eamets 2007; Seifert and Tangian 2007). Composite indicators are created by combining several indicators through factor analysis or other aggregation methods (See Seifert and Tangian 2007). Composite indicators are also helpful because they can capture the substitutional and complementary relationships of different types of policies, which is one of the key aspects of flexicurity. However useful it may be, there are certain aspects to be aware of when constructing composite indicators. Firstly, there is the weighting issue. When constructing composite indicators, it is crucial that all concepts are given the right weights within the indicator. When more weight is given to a certain concept, thus more variables are included in the composite indicator that represent that concept, the outcome of both factor analysis and aggregation method will be biased towards it. For example, let's say we are running a factor analysis to derive flexicurity components and we include four variables to represent employment security, while only including one variable for each of the other concepts in our model, such as income and combination security, and internal and external numerical flexibility. The result will be that we will get an employment security factor and another one or two factors that may represent the other concepts. If we were to use the aggregation method here, the score 
representing flexicurity will be predominantly driven by the employment security scores of countries, and the countries with high scores on employment security will score high on flexicurity. This is not a problem when this weight is based on theoretical grounds. However, when that is not the case, the outcomes will be misleading.

Secondly, when using composite indicators we should make sure that the relationship between the variables are what we presume them to be. When constructing aggregate indexes based on several variables, it must be based on either one of the following two assumptions. Either that the variables are positively correlated, or that the variables measure functional equivalent concepts. In the former case, the result from the combination score will not deviate from what we find based on the single factors separately, due to its high correlation. Thus it is safe to combine these variables. In the second case, policy measures that all serve the same purpose — such as employment security — can be combined since a high score of one policy can substitute a low score on another. Again, when such assumptions are not in place, just the mere combination of variables will result in meaningless or misleading outcomes.

\section{Short Preliminary Empirical Example}

In this section, using a narrow definition of flexicurity as an example, I will show how one can use the framework and the aspects of caution given in this paper through the use of empirical data.

\subsection{Flexicurity Definition and Indicators}

In this paper, to provide a preliminary empirical example, I define flexicurity as the combination of external numerical flexibility, income security and (enhanced) employment security, but not necessarily restricting to EPL, unemployment benefit(UB) and ALMP as defined in the Danish golden triangle model (Madsen 2004). Using this definition, two stages of flexicurity are chosen, as mentioned in Sect. 2.2, that is, efforts and states. In addition, for the levels of flexicurity, here I will focus on the national levels, but will also try to incorporate other relevant levels into the analysis. Our focus thus can be noted as in Fig. 4.

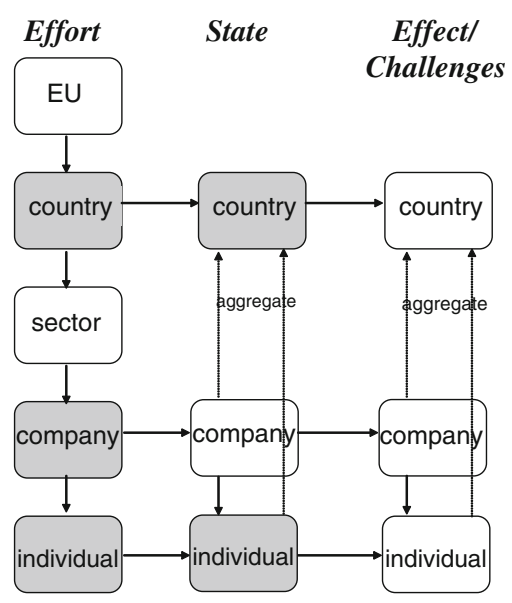

Fig. 4 The focus of the empirical analysis in this paper 
Before moving on, the various indicators that can be used to measure the concepts in our flexicurity definition will be examined.

\subsubsection{External Numerical Flexibility}

There are several variables that can be used as proxies to measure the efforts made to enhance the state of external labour market flexibility. Employment protection legislation (EPL) index is the most commonly used one in the current flexicurity debate. EPL refers to the regulations that concern hiring and firing of workers on both permanent and temporary contracts (OECD 1999:50). EPL for regular workers concerns the costs entailed for employers firing workers on permanent contracts, while EPL for temporary workers refers to the regulations concerning hiring practices. In addition, there is the collective dismissal protection index, which accounts for the differences in the regulation for collective dismissals and individual dismissals. EPL index is a proxy that measures the national leveland somewhat sector level collective bargaining-efforts in enhancing external numerical flexibility. This is due to that it is a direct measure of the policies that enable companies to hire and fire workers at a relatively easy manner, which would then enhance external numerical flexibility.

On the other hand, at the company level, temporary contracts can be used to enhance external numerical flexibility and adapt to the institutional limitations. Temporary jobs are forms of dependant employment which do not offer workers the prospect of a long-lasting employment relationship (OECD 2002:132). The key aspect to this definition, compared to the open-ended permanent contracts, is the limited time length of the contract which may derive from employers' need to adjust to the economic cycles or from the characteristics of the job. Although fix-term contracts are the biggest share of this type of employment, it also includes temporary agency workers, contracts for a specific task, replacement contracts, seasonal work, on-call work, daily workers, trainees, persons in government job creation schemes and so on (OECD 2002). This has to be distinguished from open ended contracts that are cut short by employers (or employees) terminating the contract. The use of temporary contracts is a prime example of company level efforts in enhancing external numerical flexibility.

There are several indicators that can measure the state of external numerical flexibility, including dynamic indicators such as mobility rates, but the most frequented one is the average tenure or average job duration. National average tenure is using the individual level information concerning the duration of jobs, and aggregating it to the national level, as shown in Fig. 4. This is used to represent external numerical flexibility due to that in countries with companies that fire workers more easily, or use shorter term contracts, the national average tenure will be shorter. In a very strict sense, tenure can be thought as an effect variable, thus the effect of companies using external numerical flexibility, experienced by workers. Here, I relax this assumption and take it as the proxy that measures the state of external numerical flexibility (Table 1).

\subsubsection{Income Security}

The efforts taken to enhance income security, especially for those who have lost their jobs are several. Although the unemployment benefit system (UB) is probably the main way in addressing the issue of income security in the labour market, there are other ways as well. Early retirement schemes or inactivity benefits, are all indirect ways of securing workers' income after losing one's job. To measure the level of efforts for income security, one can 
Table 1 Various external numerical flexibility variables for 19 European countries

\begin{tabular}{|c|c|c|c|}
\hline \multirow{4}{*}{$\begin{array}{l}\text { Stages } \\
\text { Levels } \\
\text { Indicators } \\
\text { Reference years }\end{array}$} & \multicolumn{2}{|l|}{ Efforts } & \multirow{2}{*}{$\begin{array}{l}\text { States } \\
\text { Individual-aggregated }\end{array}$} \\
\hline & National & Company & \\
\hline & EPL index & Temp shares & Tenure-average \\
\hline & 2008 & 2008 & 2008 \\
\hline Austria & 2.41 & 8.97 & 10.32 \\
\hline Belgium & 2.61 & 7.64 & 11.60 \\
\hline Czech Republic & 2.32 & 8.04 & 9.85 \\
\hline Denmark & 1.91 & 8.60 & 7.32 \\
\hline Finland & 2.29 & 15.09 & 9.91 \\
\hline France & 2.90 & 14.20 & 11.54 \\
\hline Germany & 2.63 & 14.58 & 10.80 \\
\hline Greece & 2.97 & 7.88 & 9.28 \\
\hline Hungary & 2.11 & 8.07 & 8.21 \\
\hline Ireland & 1.39 & 13.96 & 11.20 \\
\hline Italy & 2.58 & 7.71 & 11.27 \\
\hline Netherlands & 2.23 & 18.28 & 10.77 \\
\hline Norway & 2.65 & 9.03 & 9.15 \\
\hline Poland & 2.41 & 26.96 & 9.20 \\
\hline Portugal & 2.84 & 23.25 & 10.66 \\
\hline Spain & 3.11 & 29.39 & 8.92 \\
\hline Sweden & 2.06 & 16.05 & 10.17 \\
\hline Switzerland & 1.77 & 13.29 & 8.86 \\
\hline United Kingdom & 1.09 & 5.33 & 8.21 \\
\hline
\end{tabular}

Source OECD stat

examine the regulations in the institutions or policies to see to what extent one's income is secured. However, examining the institutions is not always sufficient, due to that every country has their own way of providing income security through various ways, such as tax benefits and through kind. For this reason, the inclusion of measures such as net replacement ratio, that is the actual income replacement rate one is likely to receive after losing one's job taking various benefit schemes and personal situations into account, and the national expenditures on the income maintenance of workers (thus spending on Passive Labour Market Policy: PLMP) add information on the various methods the income of individuals can be secured.

There are several net replacement rates (NRR) that one can take into account, depending on the duration of the unemployment and family situations. Firstly there is the initial replacement rate, which entails the replacement rate of those who have been unemployed for a short period of time. However, for most countries the benefit levels change during the unemployment period, decreasing after certain months, and then disappearing altogether or transitioning into unemployment assistance systems. For this reason it is also important to examine the long-term UB replacement rates. In addition, the benefit rates for the longerperiods also indirectly provide information on the duration of the UB systems. Here I use the initial NRR, which is most important for the unemployed for most unemployed are shorter termed, and the NRR over 60 months of unemployment to take the replacement rates for the long-term unemployed into account. In this calculation, not only the UB but 
social assistance is taken into account to see exactly how much of one's income is maintained, regardless of which benefit contributes to it. In addition, to take other income maintenance policies into account, I use the PLMP as a percentage of GDP. Table 2 shows the scores for the selected indicators for 2007, which is the latest data available. One thing to note is that these indicate the income security efforts at the national level, and not at the sectoral, company or individual level. In case of the latter levels, we can examine individual savings, or other company or sectoral income savings programmes devised to provide income security for individual workers at times of unemployment, all of which no known comparative data exists.

The state of income security can be measured through investigating the number of persons that are above a certain level of income. When we consider this income level as the poverty line, thus $60 \%$ of the median income, than at the country level the aggregate percentage of those without income security can be represented as the at-risk-poverty rate. This rate is indicated in the last column of Table 2.

\subsubsection{Employment Security}

The last aspect of flexicurity examined here is employment security. ALMP could be understood as the proxy that indicates the employment security effort at the national level, since the purpose of an extensive active labour market policy is to enhance the employability of individuals which increases the employment security of workers. The most commonly used index for measuring ALMP efforts, is the public expenditure on ALMP as a percentage of GDP. In addition to this, we can examine the various other types of activities that are not necessarily public labour market policies but enhance employability of workers. These can include life-long learning (LLL) indexes which includes both privately and publicly funded education and training, and continuous vocational training (CVT) done in enterprises. These indicators are proxies to measure the efforts to enhance employment security through training and education, taken not only at the country level but at other levels, by the company and individual themselves. These indexes can be found in Table 3.

In addition, national employment rates and unemployment rates are chosen as the national level employment security state index. Since employment security entails workers being employed, although not necessarily with the same employer, a country with many workers in employment secure positions will have a high employment rate, or a low unemployment rate. To take the time dynamic into account, long-term unemployment rates are also included.

\subsection{Differences between Levels}

In this section, I examine the relationship between the different levels of flexicurity. Thus, the question here is, are the indexes derived from different levels correspond to each other? When the answer to this question is no, this means that to grasp all actual situations of flexicurity we need to examine all levels, especially when thinking of efforts. To examine this, I take external numerical flexibility as an example. The result is that cross-nationally there is low correlation between EPL and the use of temporary contracts, which entail that there are large disparities between national level efforts of external numerical flexibility with company level efforts. In addition, although EPL for temporary workers should impact the extent to which temporary contracts are being used, actually this is not the case. We rather see a strong correlation (Spearman correlation 0.5 significant at the 0.05 level) 
Table 2 Income security indexes for 19 EU countries

\begin{tabular}{|c|c|c|c|c|}
\hline Stages & Efforts & & & State \\
\hline Level & National & National & National & Individual-aggregated \\
\hline Indicator & Initial $N_{R R}{ }^{a}$ & NRR 5 years $^{\mathrm{b}}$ & PLMP as a $\%$ of GDP & At-risk-poverty rate ${ }^{c}$ \\
\hline Reference year & 2007 & 2007 & 2007 & 2008 \\
\hline Austria & 63 & 62 & 1.25 & 11 \\
\hline Belgium & 61 & 63 & 2.00 & 12 \\
\hline Czech Republic & 67 & 61 & 0.20 & 8 \\
\hline Denmark & 73 & 77 & 1.50 & 11 \\
\hline Finland & 69 & 72 & 1.43 & 12 \\
\hline France & 74 & 60 & 1.24 & 13 \\
\hline Germany & 72 & 63 & 1.63 & 15 \\
\hline Greece & 48 & 20 & $0.38^{\mathrm{d}}$ & 19 \\
\hline Hungary & 70 & 52 & 0.36 & 12 \\
\hline Ireland & 57 & 77 & 0.91 & 14 \\
\hline Italy & 66 & 7 & 0.71 & 16 \\
\hline The Netherlands & 74 & 73 & 1.39 & 10 \\
\hline Norway & 69 & 71 & 0.42 & 11 \\
\hline Poland & 57 & 52 & 0.51 & 16 \\
\hline Portugal & 83 & 60 & 1.09 & 16 \\
\hline Spain & 70 & 49 & 1.45 & 16 \\
\hline Sweden & 66 & 68 & 0.67 & 11 \\
\hline Switzerland & 80 & 73 & n.a. & n.a. \\
\hline United Kingdom & 50 & 59 & 0.16 & 15 \\
\hline
\end{tabular}

Source OECD, tax-benefit models. www.oecd.org/els/social/workincentives. European commission, EUROSTAT

n.a. not available

a Un-weighted averages for earning levels of 67, 100, 150\% of Average Production Wage (APW) and six family types (no child single, no child one-earner married couple, no child two-earner married couple, two children lone parent, two children one-earner married couple, two children two-earner married couple). Initial phase of unemployment but following any waiting period. No social assistance "top-ups" are assumed to be available in either the in-work or out-of-work situation. Any income taxes payable on unemployment benefits are determined in relation to annualised benefit values (i.e. monthly values multiplied by 12) even if the maximum benefit duration is shorter than 12 months

b Un-weighted averages for two earning levels of 67, 100\% of APW and four family types (no child single, no child one-earner married couple, two children lone-parent, two children one-earner married couple) including social assistance. Any income taxes payable on unemployment benefits are determined in relation to annualised benefit values (i.e. monthly values multiplied by 12) even if the maximum benefit duration is shorter than 12 months. For married couples the percent of APW relates to one spouse only; the second spouse is assumed to be "inactive" with no earnings. Children are aged 4 and 6 and neither childcare benefits nor childcare costs are considered

c Cut off range: $60 \%$ of the median equivalised income after social transfers for population between 18 and 64 d 2006

between the EPL for regular workers and share of temporary workers in a country. This represents how in countries where regulations for firing workers are strict, companies use temporary contracts as an alternative method to enhance external numerical flexibility (Chung 2005; Dolado and Jimeno 2002; Polavieja 2006). 
Table 3 Employment security indexes for selected 19 European countries

\begin{tabular}{|c|c|c|c|c|c|c|}
\hline \multirow[b]{2}{*}{ Levels } & \multicolumn{3}{|l|}{ Effort } & \multicolumn{3}{|l|}{ State } \\
\hline & National & (Sector)/ & National/ & Individual-ag & regated & \\
\hline Indicator & $\begin{array}{l}\text { ALMP } \\
\text { as a \% } \\
\text { GDP }\end{array}$ & $\begin{array}{l}\text { Employees } \\
\text { participating } \\
\text { in } \mathrm{CVT}^{\mathrm{a}}(\%)\end{array}$ & $\begin{array}{l}\text { Persons in } \\
\text { any LLL } \\
(\%) \\
\text { (national/ } \\
\text { individuals) }\end{array}$ & $\begin{array}{l}\text { Employment } \\
\text { rate }^{c}\end{array}$ & $\begin{array}{l}\text { Unemployment } \\
\text { rate }^{\mathrm{d}}\end{array}$ & $\begin{array}{l}\text { Long-term } \\
\text { unemployment } \\
\text { rate }^{\mathrm{e}}\end{array}$ \\
\hline Reference year & 2007 & 2005 & 2007 & 2008 & 2008 & 2008 \\
\hline Austria & 0.51 & 33 & 13 & 72.1 & 3.8 & 0.9 \\
\hline Belgium & 1.08 & 40 & 7 & 62.4 & 7.0 & 3.3 \\
\hline $\begin{array}{l}\text { Czech } \\
\text { Republic }\end{array}$ & 0.12 & 59 & 6 & 66.6 & 4.4 & 2.2 \\
\hline Denmark & 1.02 & 35 & 29 & 78.1 & 3.3 & 0.5 \\
\hline Finland & 0.70 & 39 & 23 & 71.1 & 6.4 & 1.2 \\
\hline France & 0.69 & 46 & 8 & 64.9 & 7.8 & 2.9 \\
\hline Germany & 0.51 & 30 & 8 & 70.7 & 7.3 & 3.8 \\
\hline Greece & $0.14^{\mathrm{f}}$ & 14 & 2 & 61.9 & 7.7 & 3.6 \\
\hline Hungary & 0.21 & n.a. & 4 & 56.7 & 7.8 & 3.6 \\
\hline Ireland & 0.47 & 49 & 8 & 67.6 & 6.0 & 1.6 \\
\hline Italy & 0.37 & 29 & 6 & 58.7 & 6.7 & 3.1 \\
\hline The Netherlands & 0.68 & 34 & 17 & 77.2 & 2.8 & 1.0 \\
\hline Norway & 0.45 & 29 & 18 & 78.0 & 2.5 & 0.3 \\
\hline Poland & 0.41 & 21 & 5 & 59.2 & 7.1 & 2.4 \\
\hline Portugal & 0.39 & 28 & 4 & 68.2 & 7.7 & 3.7 \\
\hline Spain & 0.63 & 33 & 10 & 64.3 & 11.3 & 2.0 \\
\hline Sweden & 0.91 & 46 & 32 & 74.3 & 6.2 & 0.8 \\
\hline Switzerland & n.a. & n.a. & 27 & 79.5 & n.a. & n.a. \\
\hline $\begin{array}{l}\text { United } \\
\text { Kingdom }\end{array}$ & 0.05 & 33 & 20 & 71.5 & 5.6 & 1.4 \\
\hline
\end{tabular}

\section{Source EUROSTAT}

n.a. not available

a Continuous vocation training, for all industries covered, and any type of training

b LLL: percentage of adult between 25 and 64 participation in education and training in the past 4 weeks

${ }^{c}$ For population between 15 and 64

d As a percentage of the labour force

e Persons unemployed for 12 months or more as a percentage of active population

${ }^{f}$ Data from 2006

However, the disparities between levels are not necessarily the case for all elements of flexicurity. Examining the employment security indexes, the national level efforts of employment security, expressed here as expenditure on ALMP, do correspond somewhat to the company \& individual level efforts, expressed here as proportion of employees participating in CVT (Spearmans correlation of 0.5), although the relationship is insignificant. 
All in all, we can see that there is a danger in neglecting the different levels of efforts into consideration when examining flexicurity, for reasons that in some countries different actors play a rather important role, and the national level indicators may not always tell the whole story.

\subsection{Differences between Stages}

In this section, it is empirically examined why it may be dangerous to combine indexes from different stages into one single index. This can be shown via investigating the relationship between the efforts and the state indexes per concept. For the efforts, I use a standardization method to construct a composite indicator which is calculated as the formula below. This method allows us to examine the country indicator scores relative to the scores of other countries included in the analysis (for more see, OECD 2005; Seifert and Tangian 2007). Through the use of composite indicators, we are able to examine the relationship between the sum of efforts and states.

$$
y_{\mathrm{com}}=\frac{\sum_{i=1}^{n} y_{i}}{n} \quad y_{i}=\frac{x_{i}-\text { mean }}{\mathrm{SD}}
$$

Here $y_{\text {com }}$ is the composite indicators per concept, $y_{i}$ is the standardized score of the indicator $x_{i}$, using the standard deviation (SD) and mean of $x_{i}$.

As we can see from Table 4, there is not really a very high correlation between efforts with the states of flexicurity. Furthermore, we see negative correlations between the efforts and states of the flexicurity concepts. For this reason, if both efforts and state variables are included in the same index, we would not be able to interpret what is being measured through this index. In addition, since the variables may cancel out each other (given that there is a negative correlation) or at least do not correspond to one another, the result will be misleading. It must be noted that the insignificance level of the correlations may be related to the number of countries included in the analysis, which is a sample of the larger number of countries in the whole of Europe. Thus, this analysis would benefit from further validation through a larger number of country samples. However, the analysis done here serves to prove a point that, contrary to the assumptions made in previous flexicurity indicator literature, one must be careful in grouping flexicurity efforts and states as one.

Lastly, the flexicurity concepts are examined in combination to see whether the efforts and states would correspond, focusing on the fact that flexicurity emphasizes the

Table 4 Spearman correlation between Effort and States of flexicurity per concept for selected European countries

\begin{tabular}{lllll}
\hline Concept & State & Correlation & Significance & $\mathrm{N}$ \\
\hline External flexibility & Average tenure & -0.3 & n.s. & 19 \\
Income security & At-risk poverty & -0.3 & n.s. & 18 \\
Employment security & Employment rate & 0.5 & n.s. & 17 \\
& Unemployment rate & -0.3 & n.s. & 17 \\
& Long-term unemployment rate & -0.5 & Sig (0.05) & 17 \\
\hline
\end{tabular}

Source Tables 1, 2, 3

n.s. not significant

Significance level at the 0.05 or higher 
combination of flexibility and security. For this exercise, two cluster analyses are done. In the first cluster analysis, flexicurity efforts are used as input variables, to find clusters of flexicurity efforts. In the second cluster analysis, flexicurity state variables are used as the input variables, to find the cluster of flexicurity states. We can then compare the two to find the similarities or differences found between the flexicurity efforts and states. In the second cluster analysis for the flexicurity states, employment security state indicators are made into one composite indicator, so that one variable is included for each of the concepts measured here. The result is as Tables 5 and 6 .

For flexicurity efforts, four clusters are found. First cluster includes the Northern European countries, Finland and Sweden, and the two most notable flexicurity countries, that is, Denmark and the Netherlands. These countries show above average efforts in enhancing external numerical flexibility, as well as strong efforts in enhancing both income and employment security of their workers. The second group consists of Continental European countries, that is, Austria, Belgium, Czech Republic, France along with Norway. These countries show rather below average efforts in enhancing external numerical flexibility, and about average efforts in enhancing employment security, while showing above average efforts in providing income security. Third group is a rather mixed group, with Germany, Ireland, Spain and Portugal. This group is about average in their employment security efforts, and shows diversity in income security efforts as well as external numerical flexibility efforts. The last group, consisting of Greece, Italy, along with Poland and United Kingdom, can be characterized as showing low efforts in enhancing both income and employment security. On the other hand, this group shows rather diverse flexibility efforts, where UK and Poland show very high levels of external numerical flexibility efforts, Greece and Italy shows the lowest of all countries included.

The flexicurity state cluster analysis outcomes result in three clusters. The first cluster can be distinguished by the high income security state and above average employment security state. These countries include the northern European countries namely, Denmark, Finland, the Netherlands, Norway and Sweden, along with Austria, Czech Republic and Hungary. The second group can be characterized as having low flexibility state, low employment security state, but average income security state. The countries included in this cluster are Belgium, France, and Ireland. The last cluster has the lowest income security state, as well as a rather low employment security state. On the other hand both this and the first cluster of countries show very diverse external numerical flexibility states even within the cluster.

As we can see from the results, the clusters found from flexicurity efforts and flexicurity states are not always corresponding. The number of clusters found is different for flexicurity states and flexicurity efforts and the country groupings do not match perfectly.

Table 5 Clusters of countries according to flexicurity efforts

\begin{tabular}{llll}
\hline Countries & $\begin{array}{l}\text { External flexibility } \\
\text { effort }\end{array}$ & $\begin{array}{l}\text { Income security } \\
\text { effort }\end{array}$ & $\begin{array}{l}\text { Employment security } \\
\text { effort }\end{array}$ \\
\hline $\begin{array}{l}\text { Denmark, Finland, The Netherlands, } \\
\text { Sweden }\end{array}$ & Medium to high & High & High to medium \\
$\begin{array}{l}\text { Austria, Belgium, Czech Republic, } \\
\text { France, Norway }\end{array}$ & Medium to low & Medium to high & Medium \\
$\begin{array}{l}\text { Germany, Ireland, Portugal, Spain } \\
\text { Greece, Italy, Poland, United Kingdom }\end{array}$ & $\begin{array}{l}\text { Medium to high } \\
\text { Low (GR/IT) to high } \\
\text { (PO/UK) }\end{array}$ & $\begin{array}{l}\text { Low } \\
\text { Low to high }\end{array}$ & Medium \\
\hline
\end{tabular}

Cluster analysis method: ward method, squared euclidian distance 
Table 6 Clusters of countries according to flexicurity states

\begin{tabular}{|c|c|c|c|}
\hline Countries & $\begin{array}{l}\text { External } \\
\text { flexibility } \\
\text { state }\end{array}$ & $\begin{array}{l}\text { Income } \\
\text { security } \\
\text { state }\end{array}$ & Employment security state \\
\hline $\begin{array}{l}\text { Austria, Czech Republic, Denmark, Finland, } \\
\text { Hungary, The Netherlands, Norway, Sweden }\end{array}$ & $\begin{array}{l}\text { Mixed (high } \\
\text { to low) }\end{array}$ & High & $\begin{array}{l}\text { High to medium (with the } \\
\text { exception of Hungary: low) }\end{array}$ \\
\hline Belgium, France, Ireland & Low & Medium & $\begin{array}{l}\text { Low (with the exception of } \\
\text { Ireland: medium) }\end{array}$ \\
\hline $\begin{array}{l}\text { Germany, Greece, Italy, Poland, Portugal, Spain, } \\
\text { United Kingdom }\end{array}$ & $\begin{array}{l}\text { Mixed (high } \\
\text { to low) }\end{array}$ & Low & $\begin{array}{l}\text { Low (with the exception of } \\
\text { UK: medium) }\end{array}$ \\
\hline
\end{tabular}

Cluster analysis method: ward method, squared euclidian distance

In other words, although flexicurity states may be impacted by flexicurity efforts made, it does not explain it completely. This may be a result of the fact that the countries that are in bad flexicurity states may be those who are putting more efforts into increasing their flexicurity statuses. However, examining this relationship in more detail, there is no clear relationship found with flexicurity state and effort where low states always lead to higher efforts and vice versa. Regardless of the reason behind the discrepancy between flexicurity efforts and states, we can conclude that they do not correspond to one another. Thus it can cause a problem when these two concepts are grouped into one composite indicator, based on the presumption that they are highly correlated.

\section{Discussion}

In this paper I have elaborated on the various issues that should be taken into account when doing flexicurity analysis, as well as the framework, namely the stages and levels of flexicurity, that can be used to overcome some of these problems. Using the framework proposed, some preliminary analysis is done to show how the framework can be used. The country clusters provided here are by no means presented as the end of all flexicurity analyses. On the contrary, the analyses provide evidence to prove the point that it is very important to review which flexicurity indicators, at which levels and stages, are included in the analyses as well as to review the methods used. The indicators and methods selected will determine the country grouping or country scores on flexicurity. This is due to the fact that the stages of flexicurity do not necessarily correspond to each other, nor do the levels, as seen from the analysis outcomes of this paper. Thus, it is crucial to clarify which levels and stages of flexicurity are being addressed, and present the results according to the focus one has taken, stating the limitations that come with it. This is a point seldom mentioned in the current flexicurity discussion, which results in an abundance of flexicurity indicators studies without any clear conclusions or agreements between the studies.

It should also be noted that this task of deriving flexicurity indicators is a highly politically sensitive one. This is especially true for the list of indicators that will be set up by the European Commission. The CEC indicators will also be used to evaluate and access the positions or the pathways the member states are in, as well as their policy outcomes, and will be the basis for policy recommendations. Due to this reason, it will be crucial that there is first an agreement among the member states on what the definition and goals of flexicurity or measuring flexicurity across countries are. The set of indicators for the EC and member states would have to be simple enough for all member states and the social 
partners to understand and apply. Also, the set of indicators would have to be easily measurable with data sets that are comparable across countries, most preferably using reliable data sets, such as the ones from EUROSTAT. For scholars and policy makers, the purposes of flexicurity studies would not be very different. However, the set of indicators in academic research can be more diverse to encompass the complexity of policies and reality. One aspect that increases the complexity of flexicurity measurement but requires more attention is the distinction between various groups of population that need to be examined separately. These are the vulnerable groups of society, for example, the lowskilled, women, youth, older workers and migrant workers. Developing two sets of indicators may be a good solution. One simplified set of indicators could be developed to increase the ease of delivery and understanding by the member states and their actors. Another more complex set of indicators could also be developed by and for scholars to capture greater complexity.

In conclusion, it may be impossible to have one end all set of indicators of flexicurity that can be used for all circumstances, for policy makers as well as academics. This is due to the fact that the measurements and indicators included depend heavily on the definition, operationalisation, and the key research interest each person has with regards to flexicurity. Every person/group has different ideas and academic and political goals in setting forth flexicurity research, thus the result will vary accordingly. For a unified set of indicators for flexicurity to be agreed upon, there must first be an agreement on the definition on what flexicurity actually is, and the purpose of why we need to measure flexicurity and compare it across countries. If not, the indicators derived will be meaningless and it will be hard to convince others of its justification.

The analyses done in this paper are also not without limitations. Most of the analyses have been done with a sample of countries from the larger number of countries in Europe, and some of the analysis outcomes may be influenced by the countries included. In addition, our data comes from a specific time period, between 2005 and 2008, which may also influence the analysis outcomes. Thus for further validation of the points mentioned, repeated studies based on larger pool of countries and different years would be of help.

Open Access This article is distributed under the terms of the Creative Commons Attribution Noncommercial License which permits any noncommercial use, distribution, and reproduction in any medium, provided the original author(s) and source are credited.

\section{References}

Anxo, D., \& O'Reilly, J. (2000). Working-time regimes and transitions in comparative perspective. In J. O’Reilly, I. Cebrián, \& M. Lallement (Eds.), Working-time changes: Social integration through transitional labour markets (pp. 61-90). Cheltenham: Edward Elgar.

Bekker, S., \& Chung, H. (2009). Restructuring organisations while striving for flexicurity: connecting the European level to national contexts. In M. A. Moreau (Ed.), Building anticipation of restructuring in Europe. Brussels: P.E. Lang Publishers.

Bredgaard, T., \& Tros, F. (2008). Flexicurity and human resources management for older workers in the Netherlands, Denmark, Germany and Belgium. In R. Blanpain \& L. Dickens (Eds.), Challenges of European employment relations: Employment regulation, trade union organization, equality, flexicurity, training and new approaches to pay (pp. 73-100). Alphen aan den Rijn: Kluwer Law International BV.

Castonguay, J. (2009). Benchmarking carrots and sticks: an international evaluation of work-based employment programs in five countries. Amsterdam: University of Amsterdam.

CEC. (2006a). Employment in Europe 2006. Luxembourg: Commission of European Communities (CEC). 
CEC. (2006b). Flexibility and security in the EU labour markets Employment in Europe 2006 (pp. 75-118). Luxembourg: Office for Official Publications of the European Communities.

CEC. (2007a). Employment in Europe 2007. Luxembourg: Commission of European Communities.

CEC. (2007b). Towards common principles of flexicurity: More and better jobs through flexibility and security. COM. (2007) 359. Communication from the Commission to the European Parliament, the Council, the European Economic and Social Committee and the Committee of the Regions. Office for Official Publications of the European Communities. Luxembourg.

Chung, H. (2005). Different paths towards flexibility: deregulated employment protection or temporary employment: A study of cross-national variance on employment protection legislation and temporary employment in 19 OECD countries. Edinburgh: MSc Research, Edinburgh University.

Chung, H. (2007). Flexibility for employers or for employees? A new approach to examining labour market flexibility across Europe using company level data. In H. Jørgensen \& P. K. Madsen (Eds.), Flexicurity and beyond: Finding a new agenda for the European social model (pp. 243-277). Copenhagen: DJØF Publishing.

Chung, H., Muffels, R., \& Wilthagen, T. (2009). Defining and testing flexicurity indicators in Europe: How well performs the Dutch labour market comparably? OSA Report A236. Tilburg: OSA.

Dasgupta, S. (2001). Employment security: conceptual and statistical issues. Geneva: ILO.

Den Dulk, L. (2005). Workplace work-family arrangements: A study and explanatory framework of differences between organizational provisions in different welfare states. In S. A. Y. Poelmans (Ed.), Work and family: An international research perspective (pp. 211-238). Manwah: Lawrence Erlbaum Associates Inc.

Dolado, J. J., \& Jimeno, J. F. (2002). Drawing lessons from the boom of temporary jobs in Spain. The Economic Journal, 112(480), 270-295.

EMCO. (2009). Monitoring and analysis of flexicurity policies. Brussels: European Commission.

Evans, J. M. (2002). Work/family reconciliation, gender wage equity and occupational segregation: the role of firms and public policy. Canadian Public Policy/Analyse de Politiques, 28(1), 187-216.

Klammer, U., \& Tillman, K. (2001). Flexicurity-Soziale Sicherung und Flexibilisierung der Arbeits-und Lebensverhältnisse WSI-discussion paper. Düsseldorf: WSI-HBS.

Madsen, P. K. (2004). The Danish model of 'flexicurity'. Transfer, 10(2), 187-207.

Muffels, R. J. A., Chung, H., Fouarge, D., Klammer, U., Luijkx, R., Manzoni, A., et al. (2008). Flexibility and security over the life course. Luxembourg: European Foundation for the Improvement of Living and Working Conditions. Office for Official Publications of the European Communities.

OECD. (1999). Employment protection and labour market performance OECD employment outlook 1999 (pp. 49-132). Paris: OECD.

OECD. (2002). Taking the measure of temporary employment OECD employment outlook (pp. 127-185). Paris: OECD.

OECD. (2005). Handbook on constructing composite indicators: Methodology and user guide OECD Statistics working paper. Paris: OECD.

Pacelli, L., Devicienti, F., Maida, A., Morini, M., Poggi, A., \& Vesan, P. (2008). Employment security and employability: A contribution to the flexicurity debate. Luxembourg: European Foundation for the Improvement of Living and Working Conditions.

Philips, K., \& Eamets, R. (2007). Approaches to Flexicurity: EU models. Luxembourg: European Foundation for the Improvement of Living and Working Conditions.

Pierson, P. (2004). Politics in time: History, institutions, and social analysis. New York: Princeton University Press.

Polavieja, J. G. (2006). The incidence of temporary employment in advanced economies: why is Spain different? European Sociological Review, 22(1), 61.

Seifert, H., \& Tangian, A. (2007). Flexicurity: Reconciling social security with flexibility; empirical findings for Europe WSI-discussion paper Düsseldorf: WSI-HBS.

Spicker, P. (2006). Policy analysis for practice: Applying social policy. Bristol: Policy Press.

TUC. (2005). Challenging times: Flexibility and flexible working in the UK: TUC assessment of flexible working in the UK. London: Trade Union Congress.

Viebrock, E., \& Clasen, J. (2009). Flexicurity and welfare reform: A review. Socio-Economic Review, 7(2), $305-331$.

Wilthagen, T. (1998). Flexicurity? A new paradigm for labour market reform. WZB discussion paper FSI, pp. 98-202.

Wilthagen, T., \& Tros, F. (2004). The concept of 'flexicurity': A new approach to regulating employment and labour markets. Transfer, 10(2), 166-186. 